\title{
Effects of salinity on the characteristics of biomass and membrane fouling in membrane bioreactors
}

Jang, D.; Hwang, Yuhoon; Shin, H.; Lee, W.

Published in:

Bioresource Technology

Link to article, DOI:

10.1016/j.biortech.2013.02.062

Publication date:

2013

Link back to DTU Orbit

Citation (APA):

Jang, D., Hwang, Y., Shin, H., \& Lee, W. (2013). Effects of salinity on the characteristics of biomass and membrane fouling in membrane bioreactors. Bioresource Technology, 141, 50-56.

https://doi.org/10.1016/j.biortech.2013.02.062

\section{General rights}

Copyright and moral rights for the publications made accessible in the public portal are retained by the authors and/or other copyright owners and it is a condition of accessing publications that users recognise and abide by the legal requirements associated with these rights.

- Users may download and print one copy of any publication from the public portal for the purpose of private study or research.

- You may not further distribute the material or use it for any profit-making activity or commercial gain

- You may freely distribute the URL identifying the publication in the public portal

If you believe that this document breaches copyright please contact us providing details, and we will remove access to the work immediately and investigate your claim 


\section{Accepted Manuscript}

Effects of Salinity on the Characteristics of Biomass and Membrane Fouling in Membrane Bioreactors

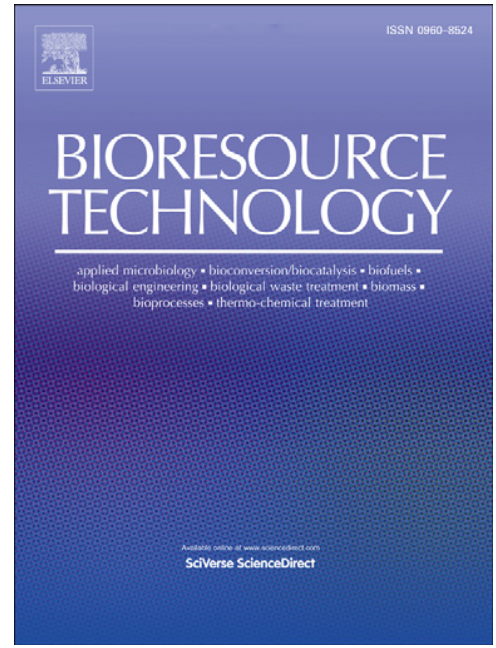

Duksoo Jang, Yuhoon Hwang, Hangsik Shin, Wontae Lee

PII: S0960-8524(13)00297-6

DOI: http://dx.doi.org/10.1016/j.biortech.2013.02.062

Reference: BITE 11401

To appear in:

Bioresource Technology

Please cite this article as: Jang, D., Hwang, Y., Shin, H., Lee, W., Effects of Salinity on the Characteristics of Biomass and Membrane Fouling in Membrane Bioreactors, Bioresource Technology (2013), doi: http://dx.doi.org/10.1016/ j.biortech.2013.02.062

This is a PDF file of an unedited manuscript that has been accepted for publication. As a service to our customers we are providing this early version of the manuscript. The manuscript will undergo copyediting, typesetting, and review of the resulting proof before it is published in its final form. Please note that during the production process errors may be discovered which could affect the content, and all legal disclaimers that apply to the journal pertain. 


\title{
Effects of Salinity on the Characteristics of Biomass and Membrane Fouling in Membrane Bioreactors
}

Duksoo Jang ${ }^{1}$, Yuhoon Hwang ${ }^{1,2^{*}}$, Hangsik Shin ${ }^{1}$, Wontae Lee ${ }^{3 *}$

${ }^{1}$ Department of Civil and Environmental Engineering, KAIST, 291 Daehak-ro, Yuseong-gu, Daejeon, 305701, Republic of Korea

${ }^{2}$ Department of Environmental Engineering, Technical University of Denmark, Miljoevej, Building 113, 2800 Kgs. Lyngby, Denmark

${ }^{3}$ School of Civil and Environmental Engineering, Kumoh National Institute of Technology, 61 Daehak-ro, Gumi, Gyeongbuk 730-701, Republic of Korea

* Corresponding author

Tel: +82-54-478-7636, email: wtlee@kumoh.ac.kr

Tel: +45-4525-2713, email: yuoh@env.dtu.dk

\begin{abstract}
This study investigated the effects of high salinity on the performance and membrane fouling of membrane bioreactor (MBR) with saline wastewater. Synthetic wastewaters containing 5 to $20 \mathrm{~g} / \mathrm{L}$ salts $(\mathrm{NaCl})$ were treated in identical lab-scale $(7 \mathrm{~L}) \mathrm{MBRs}$ monitoring removals of dissolved organic carbon (DOC) and ammonia. Increase in salt concentrations did not significantly change the removal efficiency of DOC in the MBRs. However, the ammonia removals decreased from $87 \%$ to $46 \%$ with increasing salt concentrations. PCR-DGGE analysis indicated changes in the microbial communities' composition due to high salinity; and the changes in microbial composition in turn have affected the performance of the MBRs. Membrane fouling was accelerated by the increased pore blocking resistance at higher salt concentrations. Analysis results of physicochemical and biological characteristics of biomass (EPS, floc size, zeta potential) verified the impacts of high salinity on the increased membrane fouling.
\end{abstract}

\section{Keywords}

Salinity; Membrane fouling; Membrane bioreactor; Biomass characteristics, PCR-DGGE 


\section{INTRODUCTION}

Industrialization has led not only to increased water demand, but also to deterioration of water quality, mostly due to industrial discharges. Many industries such as food processing, canning, petroleum, and petrochemical industries generate very large amounts of saline wastewater, rich in both salt and organic matters (Lefebvre \& Moletta, 2006). When these wastewaters are discharged without proper treatment, they can impair the water quality of surface and ground waters.

Saline wastewater is usually treated through physicochemical treatment processes. However, physicochemical technologies are generally energy-consuming, and their capital and operation and maintenance $(\mathrm{O} \& \mathrm{M})$ costs are relatively high. Alternative unit processes for saline wastewater treatment include anaerobic or aerobic biological treatments. However, salinity is known to have toxic effects on bacteria and is also capable of altering microbial characteristics. A number of researchers have studied and identified the significant impacts of high salinity on conventional wastewater treatment processes such as sequencing batch reactors (SBR) and activated sludge processes (ASP) (Campos et al., 2002; Panswad \& Anan, 1999; Rene et al., 2008).

The effects of salinity on sludge properties have been extensively reported (Kargi \& Dincer, 1996). First, the density of saline water is higher than that of freshwater, creating greater resistance to decantation through higher buoyant forces. Second, high salt concentrations cause cell plasmolysis and death of microbes usually present in sewage due to the increase of osmotic pressure, which results in a reduction in particle size and density. Third, hyper-salinity reduces the amount of filamentous bacteria, which play an important role in the mechanical integrity and structure of the flocs. Finally, the lack of protozoans can also increase effluent turbidity. 
One of the technologies that can potentially be utilized to overcome these negative impacts is the membrane bioreactor (MBR). The MBRs offer many benefits over the conventional activated sludge processes, which include small space and reactor requirements, better effluent quality, increased volumetric loadings, and less sludge production (Oppenheimer et al., 2001). Additional advantages would include better control of solids retention time (SRT), operational reliability and stability, easy automatic control, and compactness of the whole system. In addition, acclimation to a specific wastewater can take place at higher rates in MBR than in a continuous stirred tank reactor (CSTR) or other high rate bioreactors due to elimination of wash out (Vyrides \& Stuckey, 2011). Moreover, the MBRs were known to be capable to treat not only high strength wastewater but also toxic compounds (Guo et al., 2012).

However, membrane fouling represents one of the biggest challenges that hinder the extended utilization of membrane bioreactor process. The reduction in permeate flux is known to be the main factor in determining the economic feasibility of membrane processes (Guo et al., 2012). Membrane fouling can be caused by several factors, which, at the same time, are affected by a set of parameters such as the compositions of the biological system (Stuckey, 2012). Nevertheless, the influence of high salt concentrations on the filtration performance and membrane fouling in MBRs has not been elucidated.

Therefore, it is imperative to assess the influence of microbial characteristics under high salinity conditions on membrane permeability and fouling for further application of MBRs when managing high salinity wastewater. In this study, changes in the microbial properties of biomass in MBRs were investigated under various salinity conditions along with their influence on membrane filtration and fouling. 


\section{MATERIALS AND METHODS}

\subsection{Experimental set-up}

A lab scale submerged MBR was used. The MBR system consisted of an activated sludge bioreactor having an effective volume of $7 \mathrm{~L}$, in which a hollow fiber membrane module was placed. The membranes are made of high density polyethylene (HDPE) with a nominal pore size of $0.4 \mu \mathrm{m}$ and an effective filtration area of $0.1 \mathrm{~m}^{2}$. The sludge for the bioreactors were obtained from the activated sludge process of a wastewater treatment plant in Daejeon, Republic of Korea, and was acclimated with synthetic wastewater for 30 days before our experiments. Synthetic wastewater having influent COD of 1,200 mg/L (COD:N:P = 100:10:2) was supplied to the bioreactor from storage tank. The composition of the synthetic wastewater is summarized in Table 1; four different salt concentrations of $0,5,10$, and $20 \mathrm{~g} / \mathrm{L}$ were applied. Each of the shock loads was administered continuously throughout the experimental period. The solid retention time (SRT) could be obtained by the amount of excessive sludge discharge per day and was maintained for 50 days. Permeation of membranes was continuously maintained by using a peristaltic pump at a constant flux $3.5 \mathrm{Lm}^{-2} \mathrm{~h}^{-1}$ and hydraulic retention time (HRT) of 18 hours. The air flow rate was kept at $5 \mathrm{~L} / \mathrm{min}$. One cycle consisted of 9 min of filtration and $1 \mathrm{~min}$ of backwash. The experiments were conducted at room temperature $\left(20 \pm 5^{\circ} \mathrm{C}\right)$.

\subsection{Analytical items and methods}

The following parameters were determined based on the APHA Standard Methods (APHA, 2005): TSS by method 2540D; VSS by method 2540E; DO by method 4500-O G using a DO meter (Orion 810, Thermo scientific, MA, USA); $\mathrm{pH}$ by method 4500-H+ B using $\mathrm{pH}$ meter (Orion 720A, 
1 Thermo scientific, USA); dissolved organic carbon (DOC) by a TOC analyzer (Appollo 9000,

Teledyne Tekmar, USA) after filtration of the samples with $0.45 \mu \mathrm{m}$ syringe filters (Whatman, UK); ammonia by method $4500-\mathrm{NH}_{3} \mathrm{C}$ titrimetric method after distillation with a distilling unit (KJELTEC 1026, FOSS, Denmark). The extracellular polymeric substance (EPS) was extracted by a thermal extraction (Chang \& Lee, 1998). Carbohydrates in the EPS were determined according to the phenol-sulfuric acid method with glucose as the standard (DuBois et al., 1956). Proteins were determined by the Folin method with bovine serum albumin as the standard (Lowry et al., 1951). Particle size of activated sludge in the MBR was measured by a LS230 (Beckman, USA), in a range of 0.5 to $875 \mu \mathrm{m}$. Zeta potential was analyzed by a zeta potential analyzer (ELS-Z2, Otsuka Electronics Co. Ltd., Japan).

\subsection{Resistance analysis}

The resistance-in-series model was used to analyze membrane fouling resistances, which describes the permeate flux-transmembrane pressure (TMP) relationship over the entire domain of pressure. Based on this model, the permeate flux on the applied TMP can be described by Darcy's law as follows (Judd, 2008):

$$
J_{v}=\frac{1 d V}{A d t}=\frac{\Delta P}{\mu\left(R_{t}\right)}=\frac{\Delta P}{\mu\left(R_{m}+R_{c}+R_{f}\right)}
$$

where $J_{v}$ is the permeate flux, $\mathrm{m}^{3} / \mathrm{m}^{2} / \mathrm{h}$; V is the total volume of permeate, $\mathrm{m}^{3}$; $\mathrm{A}$ is the membrane area, $\mathrm{m}^{2} ; \mathrm{P}$ is TMP, $\mathrm{Pa} ; \mu$ is the permeate viscosity, $\mathrm{Pa} \bullet \mathrm{s} ; \mathrm{R}_{\mathrm{t}}$ is the total resistance, $\mathrm{m}^{-1} ; \mathrm{R}_{\mathrm{m}}$ is the intrinsic membrane resistance, $\mathrm{m}^{-1} ; \mathrm{R}_{\mathrm{c}}$ is the cake layer resistance, $\mathrm{m}^{-1}$; and $\mathrm{R}_{\mathrm{f}}$ is the fouling resistance, $\mathrm{m}^{-1}$, which is typically due to adsorption of solutes and pore blocking. 
Initially, the intrinsic membrane resistance $\left(\mathrm{R}_{\mathrm{m}}\right)$ was obtained using a new membrane module and ultrapure water. After TMP reached $27 \mathrm{kPa}$ during the MBR operation, the membrane module was removed from the reactor and washed with ultrapure water several times to remove the cake layer on the membrane surface. The washed module was put into the reactor again, and the initial TMP was monitored. The reduced portion of TMP was regarded as the resistance caused by the cake layer, while the remaining portion of TMP was regarded as the resistance caused by pore blocking.

\subsection{Microbial community analysis (PCR-DGGE)}

For the DNA extraction from microorganisms in each MBR, a Fast DNA SPIN Kit for Soil (Catalog No. 6560-200, MP Biomedicals, USA) was used. Characteristics of the primer sequences used are listed in Table 2. The procedure for PCR-DGGE was described in a previous study by the authors (Chae et al., 2006). An 8\% PAGE gel with a gradient of 40 to $60 \%$ was prepared. The gradient was adjusted by mixing the solutions. Immediately prior to loading, $150 \mu \mathrm{L}$ of $10 \%$ APS (ammonium persulfate) and $15 \mu \mathrm{L}$ of TEMED were added. P2/P3 products were used for the DGGE analysis. These samples were mixed with $2 \mathrm{X}$ loading dye, which is composed of $2 \%$ Bromophenol blue $0.25 \mathrm{ml}, 2 \%$ xylene cyanol $0.25 \mathrm{ml}, 100 \%$ glycerol $7.0 \mathrm{~mL}$, and deionized water $2.5 \mathrm{~mL}$. After finishing gel loading, the DGGE was run at $70 \mathrm{~V}$ for 8 hours in a DGGE machine (DCode System, BioRad Inc., USA.). From the finished gel, tick bands were extracted and the DNA contained in each extracted band was diluted with TE buffer $(10 \mathrm{mM}$ Tris-HCl, pH 8.0, $1 \mathrm{mM}$ EDTA). Using the DNA as a template, an additional PCR was conducted with P2/P3 (without a GC clamp) primer. The operating conditions were the same as employed for the P2/P3 PCR. These samples were purified using a MultiScreen Vacuum Manifold (Millipore, USA) and then sequenced. 
The sequences obtained after the sequencing reaction were matched with bacteria through a BLAST search.

\section{RESULTS AND DISCUSSION}

3.1 Recovery of treatment efficiency in MBR by microbial adaptation

\subsubsection{Recovery of removal efficiencies of DOC and ammonia}

The variations of DOC and ammonia concentrations in the MBR effluents were continuously monitored to investigate the effect of salt concentration on MBR performance. The results show that the treatment efficiencies gradually decreased as the salinity increased from 0 to $20 \mathrm{~g} \mathrm{NaCl} / \mathrm{L}$ in each reactor. An increase in salt concentration did not significantly change the removal efficiency of DOC in the MBR. The removal efficiency of DOC was maintained above $95 \%$ at $20 \mathrm{~g} \mathrm{NaCl} / \mathrm{L}$. As compared to other conventional treatment processes (Kinner \& Bishop, 1962; Munozcolunga \& Gonzalezmartinez, 1996), the MBRs responded well to salt shock loads. The high biomass concentrations in the MBRs can be attributed to withstand shock salt loads. In addition, the membrane would act as a barrier preventing the washout of solids and dead biomass that could contribute to increase in organics in the effluent.

On the contrary, salinity exhibited a significant negative impact on the nitrification process (Fig. 1). Removal efficiency of ammonia decreased from $87 \%$ to $46 \%$ as the salt concentration increased from 0 to $20 \mathrm{~g} \mathrm{NaCl} / \mathrm{L}$. The removal efficiency of ammonia was recovered after 30 to 40 days of operation due to adaptation of the activated sludge to the high salinity conditions (Panswad \& Anan, 1999). The decrease in removal efficiency of ammonia with increasing salt concentration was 
possibly due to washing out of dead biomass and lysed cell constituents (Lefebvre \& Moletta, 2006). According to Moussa et al. (2006), ammonia oxidizers are more sensitive to salt stress than heterotrophs removing organic matter. These previous research results indicate that nitrifiers are very sensitive to high salinity, and once they are affected or washed out, sometime will be required to reestablish them within the system due to their slow growth rates. Therefore, the longer recovery period for ammonia removal than those of organic removal could be caused by high sensitivity of ammonia oxidizer to salinity.

\subsubsection{Microbial Population Dynamics}

A comparison of the microbial community in the MBRs was conducted through a PCR-DGGE analysis. The dominant bands were selected, excised, and sequenced in order to reveal the identity of the microorganisms involved. DGGE gel band profiles of the microbial communities in the MBRs at different salt concentrations are illustrated in Fig. 2 and Table 3. Based on the banding profiles, the difference between microbial community structures at 0 and $5 \mathrm{~g} \mathrm{NaCl} / \mathrm{L}$ were minimal. This result indicated that salt loadings below $5 \mathrm{~g} / \mathrm{L}$ had little or no impact on the microbial community in the MBRs. Also, it explained why the removal efficiency of ammonia removal was not significantly affected below $5 \mathrm{~g} / \mathrm{L}$ of salt loading.

Microbial diversity reduced in the MBRs more than $5 \mathrm{~g} / \mathrm{L}$ of salt loading. Bands D, E, F, K, L, and P completely disappeared at 10 and $20 \mathrm{~g} \mathrm{NaCl} / \mathrm{L}$. However, bands A, B, G, I, an N (Nitrosomonas eutropha and Nitrosomonas europaea) were still present at $20 \mathrm{~g} / \mathrm{L}$ of salt and the intensity of bands E, $\mathrm{N}$ especially increased with salt concentration increments. This was similar to the result obtained by Bassin et al. (2012) who found that Nitrosomonas genus were still detected in SBR system even at the highest salt concentration $(20 \mathrm{~g} \mathrm{NaCl} / \mathrm{L})$. These findings indicated changes in the microbial 
communities' composition due to high salinity and the changes in microbial composition in turn many have affected the performance of the MBRs.

\subsection{Effects of salinity on membrane filtration and biomass properties in MBRs}

\subsubsection{Filtration characteristics}

To illustrate the characteristics of membrane filtration in each MBR, TMP was monitored at a constant flux at $3.5 \mathrm{Lm}^{-2} \mathrm{~h}^{-1}$. Since a peristaltic pump drove out the permeate and the pressure in the retentate did not change, the TMP increased naturally due to fouling, resulting in a decrease in permeate pressure. The membrane filtration was stopped and washed as when the TMP reached 27 $\mathrm{kPa}$, because it was difficult to maintain constant flux above this point.

Fig. 3 depicts the profiles of TMP over time in each MBR at different salt concentrations. TMP reached the critical flux $(27 \mathrm{kPa})$ after 132 hours in the control reactor at 20 days operation. However, TMP reached the critical flux within 60 hours of operation with a salt concentration of 20 $\mathrm{g} / \mathrm{L}$. The results indicated that the fouling tendency was significantly accelerated at high salt concentrations. In addition, slope of TMPs increased as the filtration time was extended in higher salt concentration. The time to reach critical flux was decreased in 46 hours with $20 \mathrm{~g} / \mathrm{L}$ of salt at 90 days operation.

The contribution of each resistance to membrane fouling was obtained by the resistance-in-series model. As shown in Fig. 4, a decrease in $R_{c}$ was observed along with increased salt concentration, whereas $R_{\mathrm{f}}$ increased from 7 to $22 \%$ of the total resistance. These results revealed that $R_{\mathrm{f}}$ led to a faster increment of TMP, causing an intense loss in permeability at high salt concentrations. With 
an increase in salt concentration from 0 to $5 \mathrm{~g} / \mathrm{L}$, did not evidence any sudden increase in membrane fouling or high TSS concentration due to biomass detachment. This was likely due to the biomass being able to adapt more easily and quickly to smaller increases in salt concentration, thus having less impact on biomass detachment.

\subsubsection{Extracellular polymeric substance (EPS) composition}

Table 4 illustrates the concentrations of EPS components (carbohydrate and protein) in microbial floc at various salt concentrations. After salt shock loadings (20 days), concentrations of both EPS carbohydrate and protein dramatically increased, and higher amounts of EPS released were observed under higher salt concentrations. It has been widely accepted that the exposure of biomass to a toxic wastewater generates substantial amounts of EPS (Vyrides \& Stuckey, 2011), and these can contribute to more severe membrane fouling compared to nontoxic wastewater (Wang \& $\mathrm{Wu}$, 2009).

Reid et al. (2006) reported that high salt levels greatly affect EPS concentrations, especially the initial period of operation with saline wastewater. This increase in EPS was mainly due to plasmolysis and release of intracellular constituents as well as the accumulation of unmetabolized and intermediate products of incomplete degradation of organic substances and microbial produced polymers. Also, composition of released EPS can significantly influence the hydrophobicity of microbial aggregates and their formation in bioreactors (Guo et al., 2012). Moreover, high molecular carbohydrates can stimulate the formation of sticky hydrogels on membrane surface (Frank \& Belfort, 2003). These release of products, can be part of the EPS would in turn influence sludge structure and membrane fouling in MBR.

\subsubsection{Zeta potential}


The activated sludge flocs are negatively charged as a result of the physicochemical interactions between microorganisms (mainly bacteria), inorganic particles (silicates, calcium phosphate, and iron oxides), exocellular polymers and multivalent cations (Urbain et al., 1993). If the amount of negative charge is large enough, colloids remain discrete and dispersed in suspension. Reducing or eliminating the charge has the opposite effect and the colloids will gradually aggregate and settle.

The zeta potential of the control reactor at 0 day was measured as $-30.4 \mathrm{mV}$, and a slight decrease in negativity was observed with an increase of salt concentration at 20 days, as depicted in Table $\mathbf{5}$. This can be attributed to neutralization of negative surface charges by the introduction of positively charged sodium ions. As the sodium (Na) concentration is increased negatively charged carbohydrate type polymer is also increased (Table 4). Also, the amount of protein type polymers contributes to positive surface charges of activated sludge and is expected to decrease zeta potential values (Kara et al., 2008). All these results turn up as a response to the concentration of sodium ions indicate that bacterial flocculation ability deteriorates at higher salt concentrations. These results are expected to change flocs' physical sludge structure and behavior.

\subsubsection{Particle size distribution}

As indicated in Table 5, a significant increment in floc size was observed when the salt concentrations increased at 20 days. However, a slight decreasing trend was observed in particle sizes after salt shock loadings in 90 days. This result may reflect degradation of the aggregate structure towards to more fragile and therefore larger structures, caused by the initial shock promoted by salt addition. Zhan (1999) reported that the amount of filamentous organisms in activated sludge flocs decreased significantly with increased salinity, while filamentous bacteria are supposed to be the backbone of activated sludge flocs contributing to the formation of large flocs 
(Wu et al., 2008). As these looser structures are also mechanically more delicate, however, their continuous erosion could be explained by aeration in MBRs. Also, the decrease in floc size was partially due to a floc breakage present in the suspension of isolated cells and microflocs. The amount of protozoa in the mixed liquor reduced with increasing the salinity. Protozoa are able to prey on dispersive microorganisms and the reduction of protozoa would result in more dispersive microorganisms (Zhan, 1999). Recent research of Dereli et al. (2012) showed that long term adaptation periods resulted in high salt tolerance under saline conditions, and then sludge was dispersed by reducing bacterial flocculation.

\subsubsection{Relationship between salt shock loadings and biomass characteristics}

The results showed that EPS (carbohydrate and protein) concentration increased gradually as the salinity increased. Certain microorganisms produce polymers for self-defense and to protect themselves against toxic compounds. This could also account for the increase in EPS with increasing salt concentration. The increase in EPS compounds could affect biomass properties: zeta potential, floc size, etc. Increased EPS concentrations decreased the zeta potential. The carbohydrate content of EPS has a positive relationship with the net surface charge. Also, an increase of salt content would promote bacterial flocculation, a phenomenon that is attributed to compression of the double electric layer. Higher EPS contents in sludge would result in greater sludge stability. Sheng et al. (2006) proposed that the sludge has a multiple-layer structure with two distinct regions. The outer region is a dispersible part, wherein dispersible sludge cells adhere together by the readily extractable EPS. The total EPS concentration decreases after a certain period after salt shock, possibly due to adaption. The decrease of EPS content leads to an increase of negativity of the floc surface and the force of adhesion is then decreased. After exposure to shear, the outer region would disperse. 


\section{CONCLUSION}

The effects of salinity on treatment efficiency and membrane filtration in MBRs with high salt loadings were investigated. Compared to the stable organic removal process, the nitrification process was significantly impeded by high salinity at the initial period. Although the microbial diversity decreased at high salt concentration, Nitrosomonas genus was still present, and their intensity of bands in PCR-DGGE increased. These findings indicated changes in the microbial communities' composition due to high salinity and the changes in microbial composition in turn many have affected the performance of the MBRs. Membrane fouling was accelerated by increased pore blocking resistance at high salt concentrations. High salinity influenced biomass properties impacting membrane filtration and fouling properties.

\section{Acknowledgement}

This research was supported by the National Research Foundation of Korea (NRF) grant (NRF2012-M1A2A2026587) and Basic Science Research Program through the NRF (NRF2012R1A1A1039250) funded by the Ministry of Education, Science and Technology.

\section{REFERENCES}

1. APHA. 2005. Standard Methods for the Examination of Water and Wastewater. APHA, Washington DC, USA.

2. Bassin, J.P., Kleerebezem, R., Muyzer, G., Rosado, A.S., van Loosdrecht, M.C., Dezotti, M. 2012. Effect of different salt adaptation strategies on the microbial diversity, activity, and settling of nitrifying sludge in sequencing batch reactors. Applied Microbiology and Biotechnology, 93(3), 1281-94. 
3. Campos, J.L., Mosquera-Corral, A., Sanchez, M., Mendez, R., Lema, J.M. 2002. Nitrification in saline wastewater with high ammonia concentration in an activated sludge unit. Water Res, 36(10), 2555-60.

4. Chae, S.R., Ahn, Y.T., Suh, C.W., Shin, H.S. 2006. Characteristics of nutrient removal and behaviors of intercellular materials and population dynamics of microorganisms in a vertical submerged membrane bioreactor (VSMBR). Trends in Biotechnology Research., New York. NOVA Science Publisher. pp. 1-37.

5. Chang, I.S., Lee, C.H. 1998. Membrane filtration characteristics in membrane-coupled activated sludge system - the effect of physiological states of activated sludge on membrane fouling. Desalination, 120(3), 221-233.

6. Dereli, R.K., Ersahin, M.E., Ozgun, H., Ozturk, I., Jeison, D., van der Zee, F., van Lier, J.B. 2012. Potentials of anaerobic membrane bioreactors to overcome treatment limitations induced by industrial wastewaters. Bioresour Technol, 122(0), 160-70.

7. DuBois, M., Gilles, K.A., Hamilton, J.K., Rebers, P.A., Smith, F. 1956. Colorimetric Method for Determination of Sugars and Related Substances. Analytical Chemistry, 28(3), 350-356.

8. Frank, B.P., Belfort, G. 2003. Polysaccharides and sticky membrane surfaces: critical ionic effects. Journal of Membrane Science, 212(1-2), 205-212.

9. Guo, W., Ngo, H.H., Li, J. 2012. A mini-review on membrane fouling. Bioresour Technol, 122(0), 27-34.

10. Judd, S. 2008. The status of membrane bioreactor technology. Trends Biotechnol, 26(2), 109-16.

11. Kara, F., Gurakan, G.C., Sanin, F.D. 2008. Monovalent cations and their influence on activated sludge floc chemistry, structure, and physical characteristics. Biotechnol Bioeng, 100(2), 231-9.

12. Kargi, F., Dincer, A.R. 1996. Effect of salt concentration on biological treatment of saline wastewater by fed-batch operation. Enzyme and Microbial Technology, 19(7), 529-537.

13. Kinner, N.E., Bishop, P.L. 1962. Treatment of saline domestic wastewater using RBCs. J. Environ. Eng., 108, 650-663.

14. Lefebvre, O., Moletta, R. 2006. Treatment of organic pollution in industrial saline wastewater: a literature review. Water Res, 40(20), 3671-82.

15. Lowry, O.H., Rosebrough, N.J., Farr, A.L., Randall, R.J. 1951. Protein measurement with the Folin phenol reagent. J Biol Chem, 193(1), 265-75.

16. Moussa, M.S., Sumanasekera, D.U., Ibrahim, S.H., Lubberding, H.J., Hooijmans, C.M., Gijzen, H.J., van Loosdrecht, M.C. 2006. Long term effects of salt on activity, population structure and floc characteristics in enriched bacterial cultures of nitrifiers. Water Res, 40(7), 1377-88. 
17. Munozcolunga, A., Gonzalezmartinez, S. 1996. Effects of population displacements on biological phosphorus removal in a biofilm SBR. Water Science and Technology, 34(1-2), 303-313.

18. Oppenheimer, J., Trussell, R., Boulos, L., Adham, S., Gagliardo, P. 2001. Feasibility of the membrane bioreactor process for water reclamation. Water Sci Technol., 43(10), 203-9.

19. Panswad, T., Anan, C. 1999. Impact of high chloride wastewater on an anaerobic/anoxic/aerobic process with and without inoculation of chloride acclimated seeds. Water Research, 33(5), 1165-1172.

20. Rene, E.R., Kim, S.J., Park, H.S. 2008. Effect of COD/N ratio and salinity on the performance of sequencing batch reactors. Bioresour Technol, 99(4), 839-46.

21. Sheng, G.P., Yu, H.Q., Li, X.Y. 2006. Stability of sludge flocs under shear conditions: roles of extracellular polymeric substances (EPS). Biotechnol Bioeng, 93(6), 1095-102.

22. Stuckey, D.C. 2012. Recent developments in anaerobic membrane reactors. Bioresour Technol, 122(0), 137-48.

23. Urbain, V., Block, J.C., Manem, J. 1993. Bioflocculation in Activated-Sludge - an Analytic Approach. Water Research, 27(5), 829-838.

24. Vyrides, I., Stuckey, D.C. 2011. Fouling cake layer in a submerged anaerobic membrane bioreactor treating saline wastewaters: curse or a blessing? Water Sci Technol, 63(12), 29028.

25. Wang, Z.W., Wu, Z.C. 2009. A Review of Membrane Fouling in MBRs: Characteristics and Role of Sludge Cake Formed on Membrane Surfaces. Separ. Sci. Technol., 44(15), 35713596.

26. Wu, G., Guan, Y., Zhan, X. 2008. Effect of salinity on the activity, settling and microbial community of activated sludge in sequencing batch reactors treating synthetic saline wastewater. Water Sci Technol, 58(2), 351-8.

27. Zhan, X. 1999. Characteristics of activated sludge processes treating saline wastewater, Vol. PhD Thesis, Tsinghua University. Beijing, China. 
Table 1. Characteristics of a synthetic wastewater

\begin{tabular}{|c|c|c|c|}
\hline Compound & Chemical formula & $\begin{array}{c}\text { Molecular weight, } \\
\text { (g/mol) }\end{array}$ & $\begin{array}{c}\text { Concentration, } \\
(\mathrm{mg} / \mathrm{L})\end{array}$ \\
\hline \multicolumn{4}{|l|}{ Organics and nutrients } \\
\hline Glucose & $\mathrm{C}_{6} \mathrm{H}_{12} \mathrm{O}_{6}$ & 180.0 & 924 \\
\hline Ammonium sulfate & $\left(\mathrm{NH}_{4}\right)_{2} \mathrm{SO}_{4}$ & 132.1 & 1,200 \\
\hline Potassium phosphate & $\mathrm{KH}_{2} \mathrm{PO}_{4}$ & 136.1 & 84 \\
\hline \multicolumn{4}{|l|}{ Trace nutrients } \\
\hline Calcium chloride & $\mathrm{CaCl}_{2} \cdot 2 \mathrm{H}_{2} \mathrm{O}$ & 147.0 & 0.368 \\
\hline Magnesium sulfate & $\mathrm{MgSO}_{4} \cdot 7 \mathrm{H}_{2} \mathrm{O}$ & 246.5 & 5.07 \\
\hline Manganese chloride & $\mathrm{MnCl}_{2} \cdot 4 \mathrm{H}_{2} \mathrm{O}$ & 197.9 & 0.275 \\
\hline Zinc sulfate & $9_{4} \cdot 7$ & 287.5 & 0.44 \\
\hline Ferric chloride anhydrous & $\mathrm{FeCl}_{3}$ & 162.2 & 1.45 \\
\hline Cupric su & $\mathrm{CuSO}_{4} \cdot 5 \mathrm{H}_{2} \mathrm{O}$ & 249.7 & 0.391 \\
\hline Cobalt chloride & $\mathrm{CoCl}_{2} \cdot 6 \mathrm{H}_{2} \mathrm{O}$ & 237.9 & 0.42 \\
\hline Sodium molybdatedihydrate & $\mathrm{Na}_{2} \mathrm{MoO}_{4} \cdot 2 \mathrm{H}_{2} \mathrm{O}$ & 242.0 & 1.26 \\
\hline Yeast extreact & & & 30 \\
\hline
\end{tabular}


Table 2. Characteristics of primers used for PCR 
Table 3. DDGE fragments of microorganisms by $16 \mathrm{~S}$ rDNA

\begin{tabular}{ccc}
\hline DGGE Bands & Closest identity & Accession number \\
\hline A & Nitrosomonas europaea (ATCC25978) & GQ451713 \\
\hline B & Nitrosomonas europaea (ATCC25978) & GQ451713 \\
\hline C & Methyloversatilis universalis (FAM5) & DQ442273 \\
\hline D & Azohydromonas lata (IAM 12599) & AB188125 \\
\hline E & Azohydromonas lata (IAM 12599) & AB188125 \\
\hline F & Dechloromonas agitata (CKB) & AF170357 \\
\hline G & Nitrosomonas europaea (ATCC25978) & GQ451713 \\
\hline H & Burkholderia megapolitana (LMG 23650) & AM489502 \\
\hline I & Nitrosomonas europaea (ATCC25978) & GQ451713 \\
\hline J & Methyloversatilis universalis (FAM5) & DQ442273 \\
\hline K & Nitrosomonas europaea (ATCC25978) & GQ451713 \\
\hline L & Shewanella japonica (KMM 3299) & KMM 3299T \\
\hline M & Schlegelella thermodepolymerans (K14) & AY152824 \\
\hline N & Nitrosomonas europaea (ATCC25978) & GQ451713 \\
\hline O & Nitrosomonas europaea (ATCC25978) & GQ451713 \\
\hline P & Nitrosomonas eutropha (C91) & Q0AG70 \\
\hline & & \\
\hline & & \\
\hline & & \\
\hline & & \\
\hline & & \\
\hline
\end{tabular}


Table 4. Variations of EPS in the MBRs at different salt shock loadings

\begin{tabular}{|c|c|c|c|c|c|}
\hline $\begin{array}{c}\text { EPS } \\
\text { composition }\end{array}$ & $\begin{array}{l}\text { NaCl shock } \\
\text { loading }(\mathrm{g} / \mathrm{L})\end{array}$ & 0 day & 20 days & 60 days & 90 days \\
\hline \multirow{5}{*}{$\begin{array}{l}\text { Carbohydrate } \\
\text { (mg/g VSS) }\end{array}$} & 0 & 4.9 & 3.1 & 3.0 & 2.6 \\
\hline & 5 & 5.2 & 8.4 & 3.3 & 2.8 \\
\hline & 10 & 4.3 & 12.6 & 4.7 & 4.5 \\
\hline & 20 & 4.0 & 16.2 & 6.5 & 6.0 \\
\hline & 0 & 2.9 & 2.5 & 3.1 & 2.9 \\
\hline \multirow{3}{*}{$\begin{array}{c}\text { Protein } \\
(\mathrm{mg} / \mathrm{g} \text { VSS })\end{array}$} & 5 & 2.7 & 4.5 & 1.9 & 1.8 \\
\hline & 10 & 3.3 & 4.7 & 1.9 & 1.5 \\
\hline & 20 & 2.3 & 4.5 & 1.8 & 1.1 \\
\hline
\end{tabular}


Table 5. Variations of particle size and zeta potential in MBRs at different salt shock loadings
NaCl shock
Particle size $(\mu \mathrm{m})$
Zeta potential $(\mathrm{mV})$

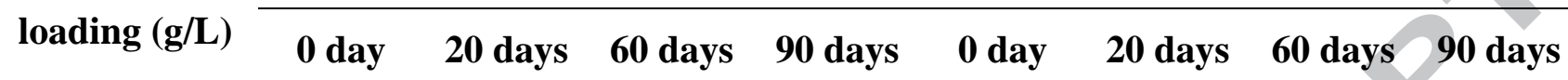

\begin{tabular}{ccccccccc}
\hline 0 & 94.7 & 118.8 & 123.3 & 149.1 & -30.4 & -34.7 & -35.1 & -34.3 \\
\hline 5 & 86.9 & 255.2 & 313.9 & 280.5 & -31.6 & -10.2 & -32.4 & -32.6 \\
\hline 10 & 79.5 & 295.0 & 326.0 & 282.3 & -31.5 & -12.8 & -33.5 & -31.5 \\
\hline 20 & 87.5 & 295.0 & 330.4 & 307.2 & -29.4 & -19.4 & -36.5 & -33.5 \\
\hline
\end{tabular}




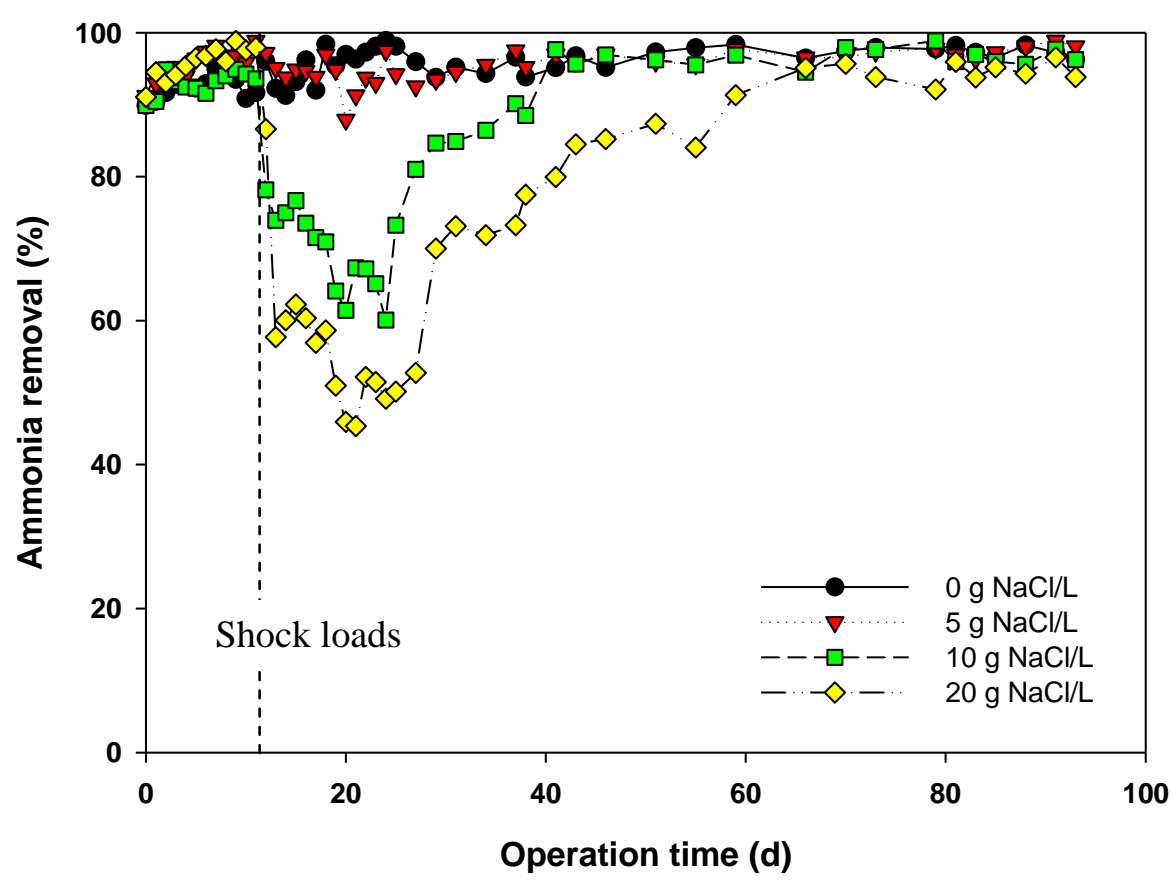


Fig. 2. DGGE gel banding profiles of microbial communities in the MBRs at different salt concentrations.

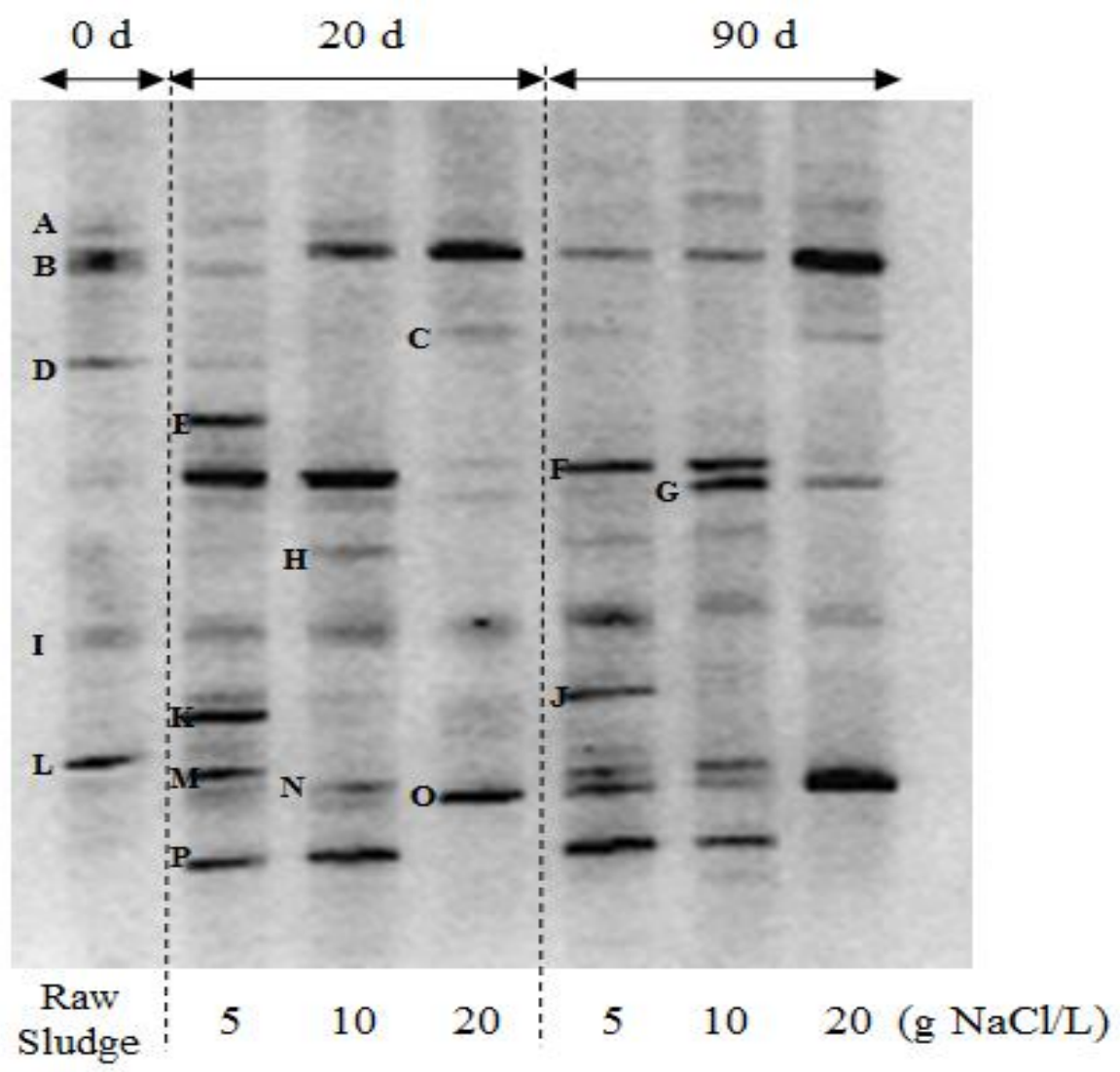


1

2

3

4

5

6

7

8

9

10

11

12

13

14

15

16

17

18

19

20

21

22

23

24

25

26

27

28

29

30

31

32

33

34

35

36

37

38

39

40

41

42

43

44

Fig. 3. Overall TMP profiles of salt shock tests.

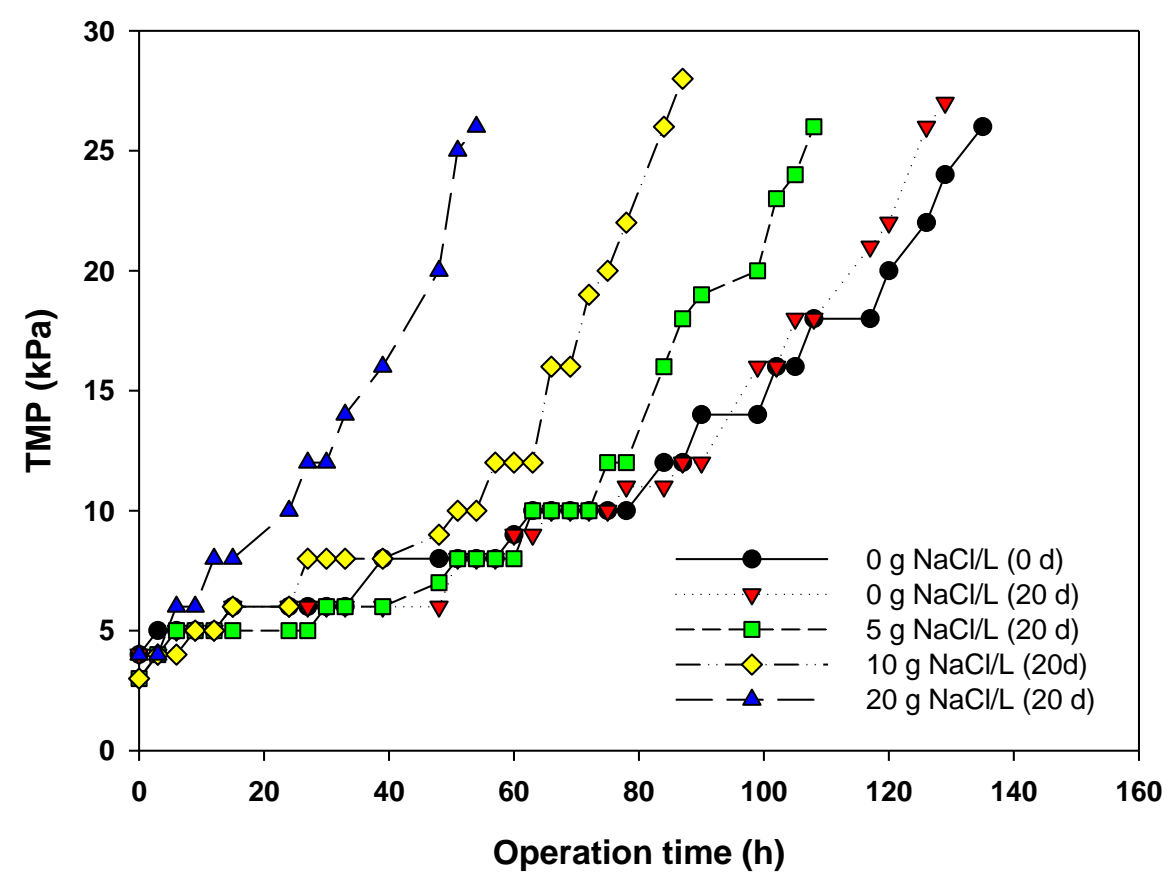

(a) 20 days

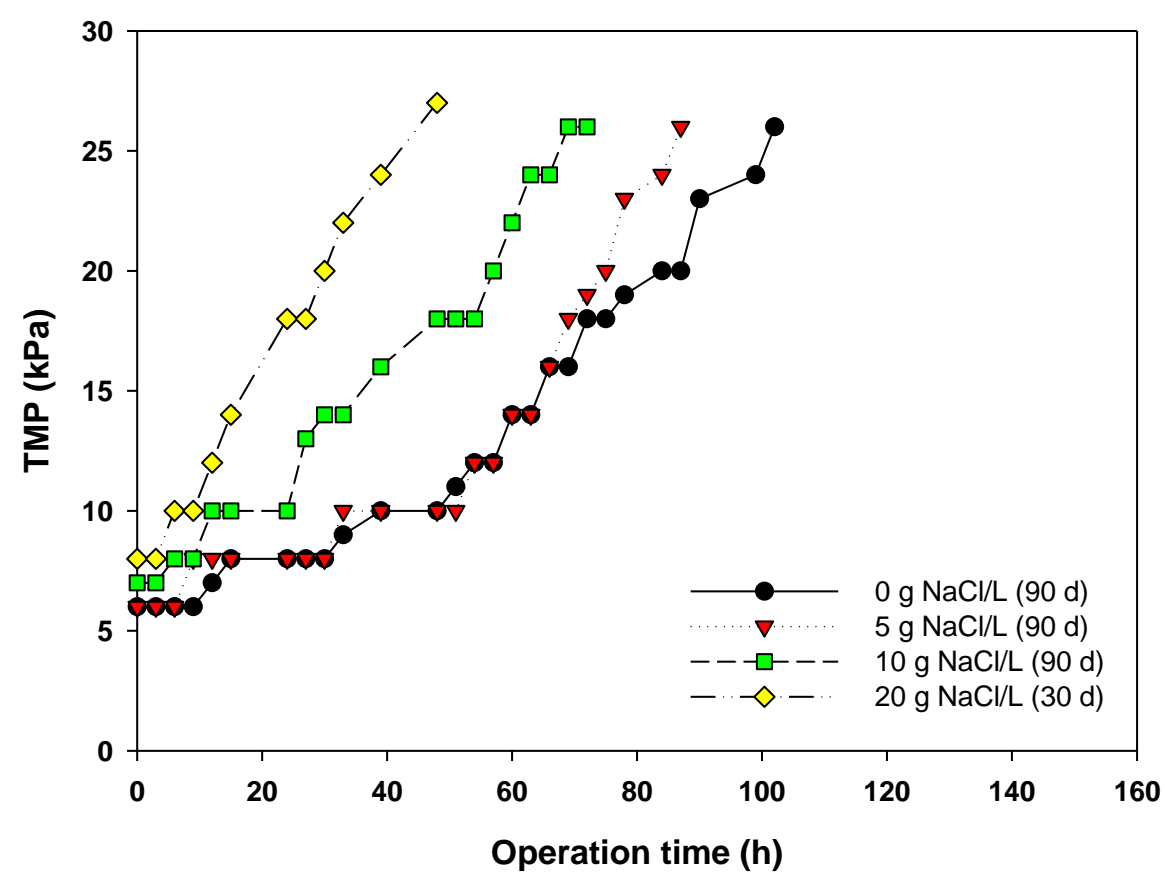

(b) 90 days 
Fig. 4. Comparison of resistances in the MBRs at various salt loadings.

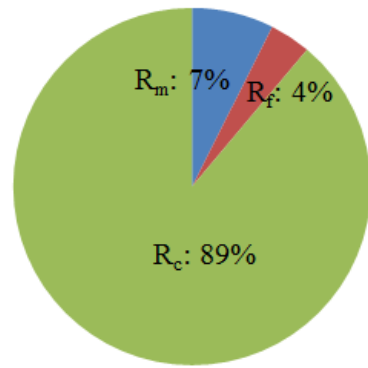

$(0 \mathrm{~g} \mathrm{NaCl} / \mathrm{L})$

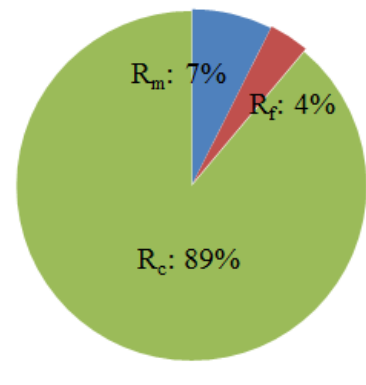

$(5 \mathrm{~g} \mathrm{NaCl} / \mathrm{L})$

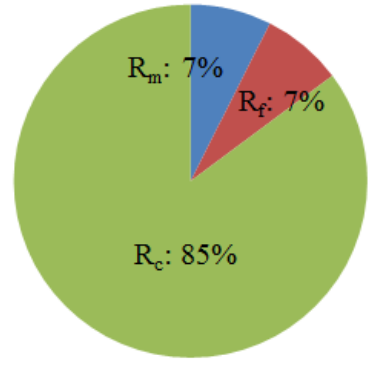

$(10 \mathrm{~g} \mathrm{NaCl} / \mathrm{L})$

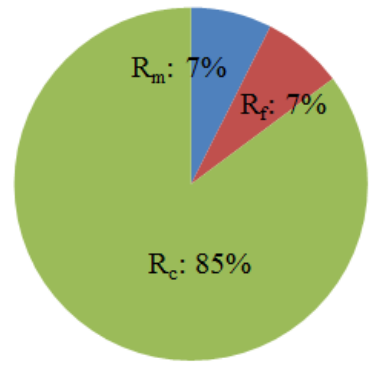

$(20 \mathrm{~g} \mathrm{NaCl} / \mathrm{L})$

(a) Initial stage (20 days)

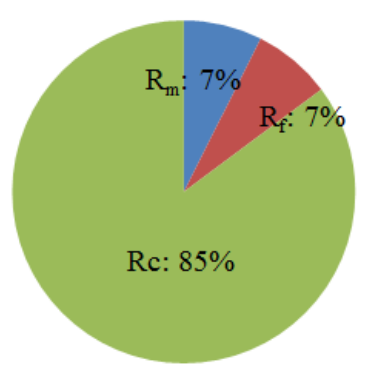

$(0 \mathrm{~g} \mathrm{NaCl} / \mathrm{L})$

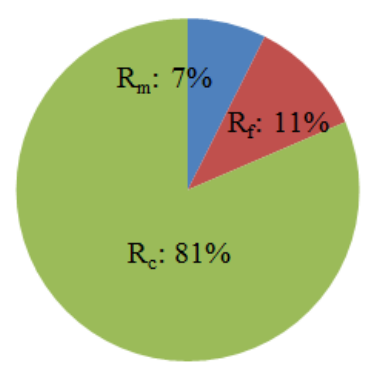

$(5 \mathrm{~g} \mathrm{NaCl} / \mathrm{L})$



$(10 \mathrm{~g} \mathrm{NaCl} / \mathrm{L})$

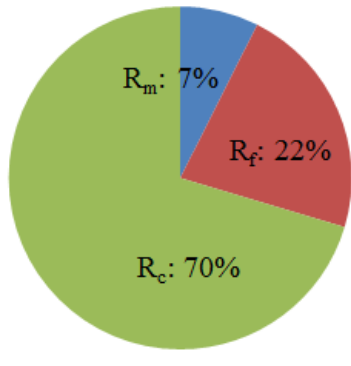

$(20 \mathrm{~g} \mathrm{NaCl} / \mathrm{L})$

(b) Finial stage (90 days) 